\title{
Analysis of the applicability of die pressing method for ring-shaped parts fabrication
}

\author{
Vladislav Lavrinenko ${ }^{1}$, Anastasiya Polyakova $^{1}$, and Artyom Polyakov ${ }^{1, *}$ \\ ${ }^{1}$ Bauman Moscow State Technical University, 5 2ya Baumanskaya Str., 105005, Moscow
}

\begin{abstract}
This paper analyses die pressing method used for fabrication of ring-shaped parts, which assures significant metal economy. Computer simulation results obtained with PAM-STAMP software are compared with experimental data. The research outcome is the established range of applicability of die-pressing method for manufacturing ring-shaped parts.
\end{abstract}

Ring-shaped parts are widely used in various engineering industries, for example in the automotive industry. Ring-shaped parts are used in the axle joints in trucks, also as stop and retaining rings for wheel-end hub bearings in semi-trailers and full trailers. Depending on the operating conditions, ring-shaped parts can be made from aluminum, steel, or bronze.

The most common manufacturing methods for ring-shaped parts are pressing (punching and cutting), stamping from hollow billets and shearing. These methods are characterized by high material and power consumption and a low material utilization factor.

A new method for producing ring-shaped parts from a sheet billet is proposed in $[1,2]$. According to this method, a punch (2) compresses an oval-shaped billet with an ovalshaped hole (1) in a die (3) covered with a lid (4).

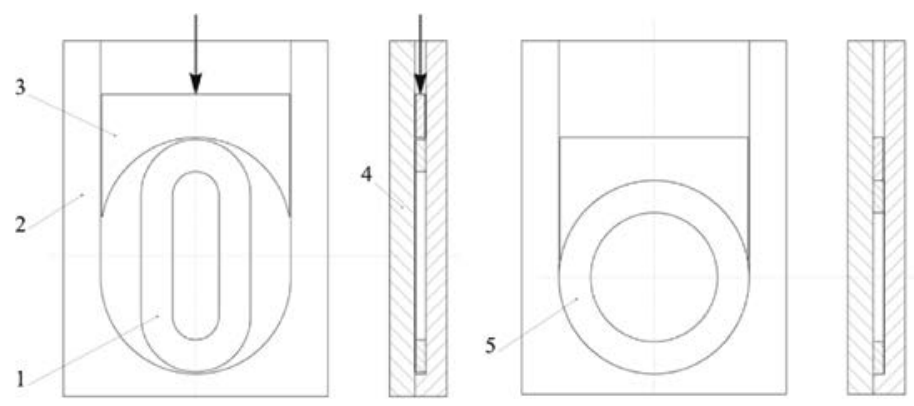

Fig. 1. Ring-shaped part fabrication. 1 billet; 2 punch; 3 die; 4 lid; 5 finished part

The purpose of this work was to analyze the applicability of the die pressing method and estimate the usage efficiency of this method for producing ring-shaped parts which OOO Machine building plant Tonar employs in trailers and semi-trailers, quarry dump trucks and high-capacity truck trains. At this enterprise, ring-shaped parts (Fig. 2) are made

\footnotetext{
* Corresponding author: artemdrezna@,mail.ru
} 
of 08 пс (08 ps) steel (GOST 1050-2013) and have the following dimensions: outer diameter $\mathrm{D}=16 \ldots 230 \mathrm{~mm}$, thickness $\mathrm{S}=1 \ldots 10 \mathrm{~mm}$, ring width $\mathrm{B}=4 \ldots 30 \mathrm{~mm}$.

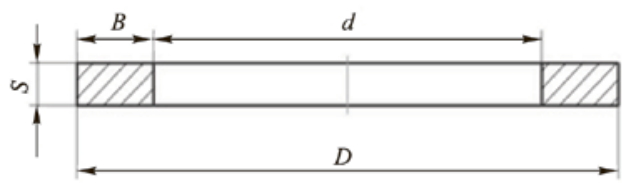

Fig. 2. Ring-shaped part

Table 1 contains the range of dimensions for ring-shaped parts to be investigated. The thickness $S$ of the primary blank, as the limiting case, is assumed to equal $1 \mathrm{~mm}$ for all ratios of $D$ and $B$.

Table 1. Range of dimensions for ring-shaped parts

\begin{tabular}{|c|c|c|}
\hline № & Outer diameter $D, \mathrm{~mm}$ & Ring width $B, \mathrm{~mm}$ \\
\hline 1 & 230 & $10 \ldots 30$ \\
\hline 2 & 124 & $6 \ldots 18$ \\
\hline 3 & 16 & 4 \\
\hline
\end{tabular}

To determine the range of applicability of the die pressing method, the PAM-STAMP software package was used to develop a computer simulation technique for the process of ring-shaped parts fabrication [3]. Geometric dimensions of the initial billet were calculated taking into account the change in the length of the middle line of the initial billet during the deformation, with the straightline part of the billet bending, and the radius part unbending [4].

The $A$ dimension for different sizes of the rings (Figure 3) was determined using the formula:

$$
A=k \pi(R-r)
$$
ratio.

where $k$ is the coefficient of the displacement of the neutral layer; it depends on the $R / B$

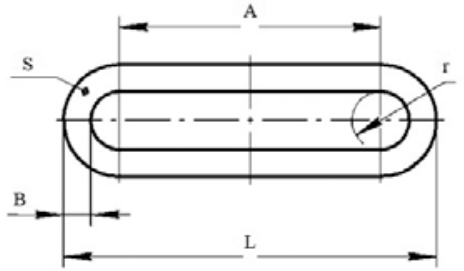

$a$

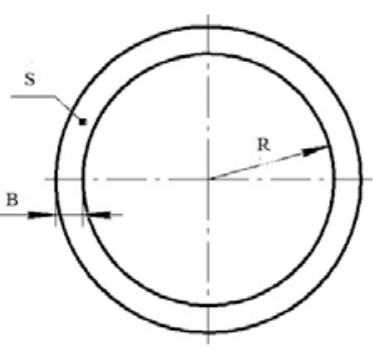

$b$

Fig. 3. Primary blank, length $L(a)$, and ring-shaped part $(b)$

The finite-element models of the die and the blank (Fig.4) were created in the PAMSTAMP software package. 


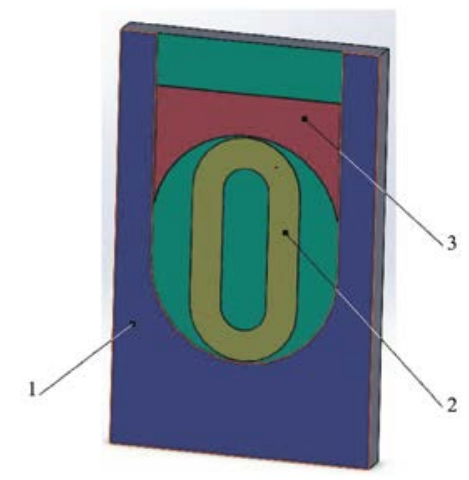

Fig. 4. Finite-element models of the die and blank. 1 die; 2 blank; 3 punch

Figs. 5-9 present results of deformation simulation of a primary oval-shaped part upon compression in the die.

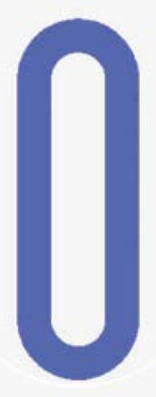

$a$

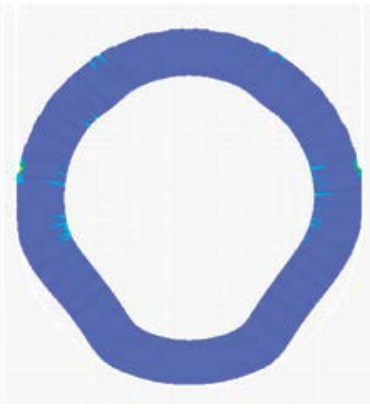

$b$

Fig. 5. Computer simulation results of the die pressing process: $a$ - primary blank; $b$ - finished part, $D=230 \mathrm{~mm}, B=30 \mathrm{~mm}$

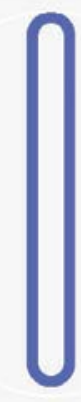

$a$

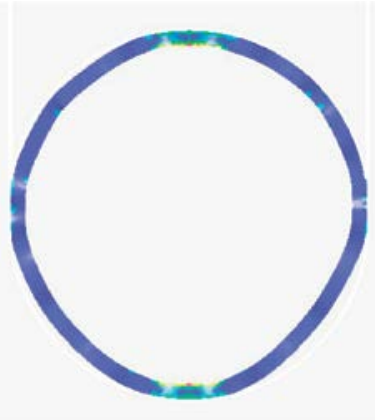

$b$

Fig. 6. Computer simulation results of the die pressing process: $a$ - primary blank; $b$ - finished part, $D=230 \mathrm{~mm}, B=10 \mathrm{~mm}$ 


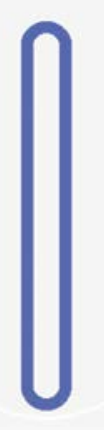

$a$

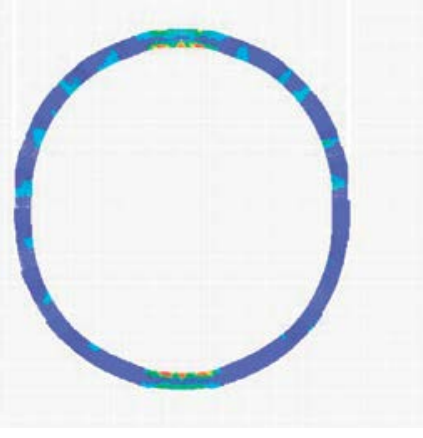

$b$

Fig. 7. Computer simulation results of the die pressing process: $a$ - primary blank; $b$ - finished part, $D=124 \mathrm{~mm}, B=6 \mathrm{~mm}$

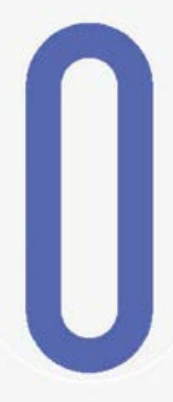

$a$

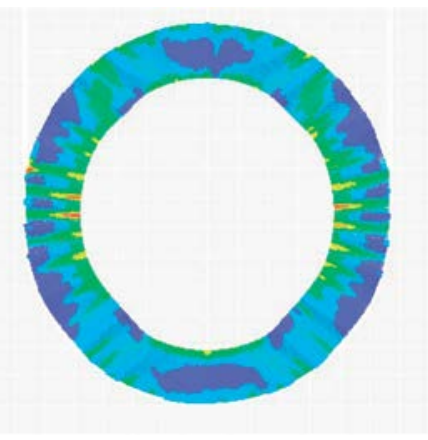

$b$

Fig. 8. Computer simulation results of the die pressing process: $a$-primary blank; $b$ - finished part, $D=124 \mathrm{~mm}, B=18 \mathrm{~mm}$

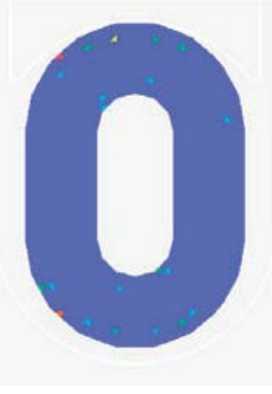

$a$

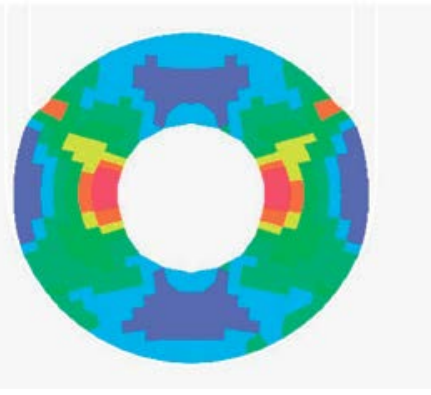

$b$

Fig. 9. Computer simulation results of the die pressing process: $a$ - primary blank; $b$ - finished part, $D=16 \mathrm{~mm}, B=4 \mathrm{~mm}$

After the analysis of the computer simulation data, the range of applicability for the pressing method was determined for the specified dimensions. The shaded area in Fig. 10 represents the area of the usage efficiency for the method under investigation. 


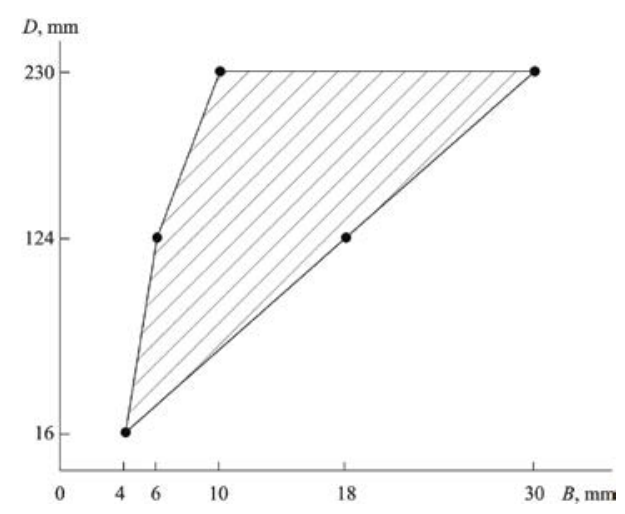

Fig. 10. Area of applicability of the pressing method for ring-shaped part fabrication within specified dimensions range

The obtained computer simulation data were verified by compressing an oval-shaped billet in an experimental die (Fig. 11) to produce a ring-shaped part, $D=82 \mathrm{~mm}, B=16$ $\mathrm{mm}, S=3 \mathrm{~mm}$; 08ps steel. The UIM-100 hydraulic press with a nominal force of $1 \mathrm{MN}$ was used.
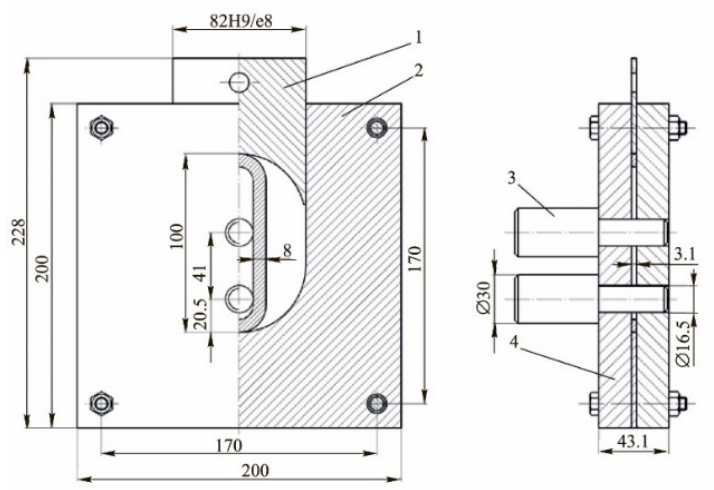

$a$

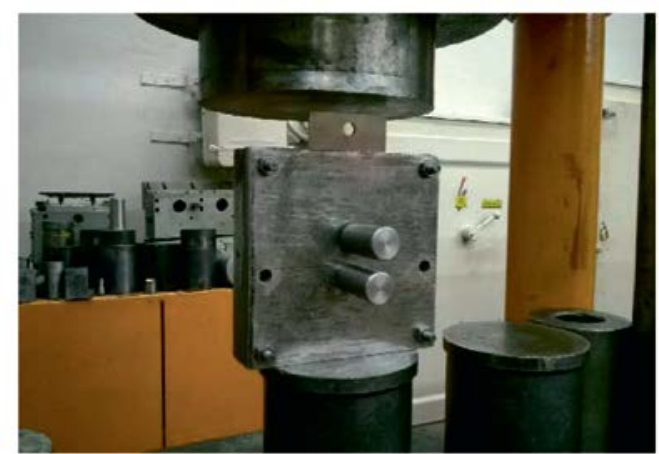

$b$

Fig. 11. Experimental die to compress an oval-shaped-billet: $a$ pressing die design; $b$ die installed onto UIM-100 
Dimensions of the primary blank $(L=118 \mathrm{~mm})$ and the finished part are shown in Fig. 12. The finished part was $82 \mathrm{~mm}$ in the outer diameter with the circumference deviation $\beta=$ $0,97 \%$.

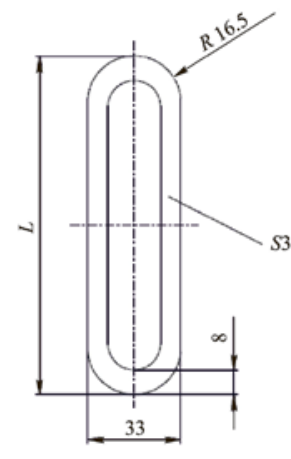

$a$

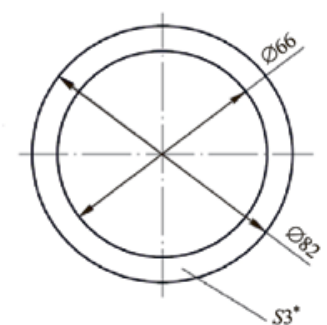

$b$

Fig. 12. Dimensions of the primary billet, $L=118 \mathrm{~mm}(a)$ and the finished part (b)

Fig. 13 shows deformation stages of the primary blank depending on the stroke length of the ram.

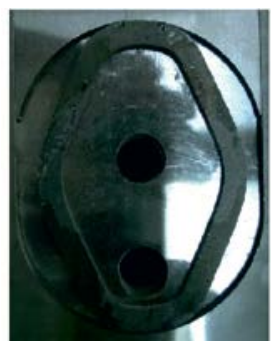

$a$

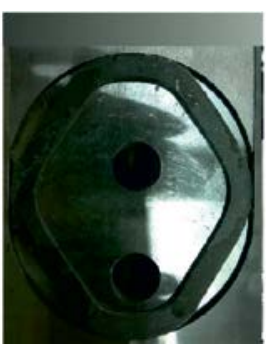

$b$

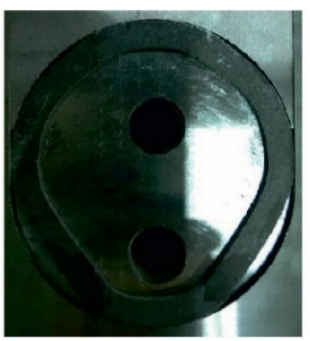

$c$

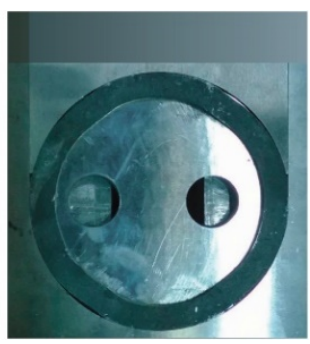

$d$

Fig. 13. Deformation stages of the primary blank depending on the stroke length of the ram: $a-16 \mathrm{~mm} ; b-24 \mathrm{~mm} ; c-30 \mathrm{~mm} ; d-36 \mathrm{~mm}$, finished ring-shaped part

\section{Conclusion}

1. The process of manufacturing ring-type parts by compressing an oval billet was simulated using the PAM-STAMP software package. The computer modelling results helped establish the range of applicability, i.e. the area of usage efficiency for the die pressing method in the specified dimensions range. This area denotes feasibility of the die pressing method for ring-shaped parts. The parts whose dimensions are outside the specified area should be fabricated using a different method (cutting and punching, stamping a hollow billet, lathe turning from a sheet blank, etc.).

2. The possibility of fabricating a ring-shaped part $(D=82 \mathrm{~mm}, B=16 \mathrm{~mm})$ using die pressing was verified experimentally. A ring-shaped part was produced with the required outer diameter of $82 \mathrm{~mm}$ and the circumference deviation $\beta=0.97 \%$, which demonstrates close convergence with the computer simulation results.

3. The obtained range of applicability can be used to develop the process design methodology for fabricating ring-shaped parts by sheet metal pressing. 


\section{References}

1. Ye.I. Semenov, V.Yu. Lavrinenko, A.S. Ayrapetyan, M.V. Demin, Ye.I. Yastrebov, Device for fabricating flat rings. RF Patent № 144991. Issued 10.09.2014. Bulletine No 25.

2. Ye.I. Semenov, A.S. Ayrapetyan, M.V. Demin, Izvestiya Tul'skogo gosudarstvennogo universiteta. Tekhnicheskiye nauki. 6-1, 296-303 (2015)

3. V.Yu. Lavrinenko, Zagotovitel'nyye proizvodstva v mashinostroyenii, 6, 15-19 (2009)

4. D.V. Rostovtsev, V.A. Demin, Ye.I. Semenov, Zagotovitel'nyye proizvodstva v mashinostroyenii, 8, 17-19 (2012) 